\title{
Foraging areas of streaked shearwaters in relation to seasonal changes in the marine environment of the Northwestern Pacific: inter-colony and sex-related differences
}

\author{
Takashi Yamamoto ${ }^{1, *}$, Akinori Takahashi ${ }^{1,2}$, Nariko Oka ${ }^{3}$, Takahiro Iida ${ }^{1,2}$, \\ Nobuhiro Katsumata ${ }^{4}$, Katsufumi Sato ${ }^{4}$, Philip N. Trathan ${ }^{5}$ \\ ${ }^{1}$ Department of Polar Science, The Graduate University for Advanced Studies, 10-3 Midori-cho, Tachikawa, \\ Tokyo 190-8518, Japan \\ ${ }^{2}$ National Institute of Polar Research, 10-3 Midori-cho, Tachikawa, Tokyo 190-8518, Japan \\ ${ }^{3}$ Yamashina Institute for Ornithology, 115 Konoyama, Abiko, Chiba 270-1145, Japan \\ ${ }^{4}$ International Coastal Research Center, Atmosphere and Ocean Research Institute, The University of Tokyo, \\ 2-106-1 Akahama, Otsuchi, Iwate 028-1102, Japan \\ ${ }^{5}$ British Antarctic Survey, Natural Environment Research Council, High Cross, Madingley Road, Cambridge CB3 0ET, UK
}

\begin{abstract}
As the spatial distribution of marine organisms is often affected by seasonal changes, pelagic seabirds may change their foraging areas in response to seasonal changes in the marine environment. Here, we examined the foraging area of streaked shearwaters Calonectris leucomelas, breeding at Sangan (SA) and Mikura Islands (MK), Japan, from spring to summer during pre-laying and incubation periods. Those colonies are located at the north and south of the Northwestern Pacific's Kuroshio-Oyashio transition area where high seasonal temperature changes are observed, and where, consequently, birds may show comparable responses to such changes. Our results showed that streaked shearwaters from both colonies shifted their foraging areas northwards as the season progressed. The seasonal shift of foraging areas appeared to coincide with the movement pattern of pelagic fishes that migrate northward in association with the increase in water temperature. However, the pattern of seasonal movement differed between the 2 colonies; shearwaters from SA moved their foraging area along the coastal area of the Kuroshio-Oyashio transition, while those from MK moved along the Kuroshio Extension. Our results also indicated sex-related differences in this general pattern: females showed clear seasonal changes in foraging area, while males did not. During the pre-laying period males returned to the colony frequently to defend their nests or mates, and spent less time at sea. Our results suggest that streaked shearwaters changed their foraging areas in response to seasonal changes in the marine environment, although colony location and sex-related differences in reproductive roles may constrain the birds' responses to seasonal change.
\end{abstract}

KEY WORDS: Streaked shearwaters $\cdot$ Northwestern Pacific $\cdot$ Seasonal change $\cdot$ Foraging $\cdot$ Kuroshio Sex-related difference $\cdot$ Pre-laying

- Resale or republication not permitted without written consent of the publisher

\section{INTRODUCTION}

Understanding the spatio-temporal dynamics of seabirds at sea is important, not only for describing their relationship with physical and biological processes in the marine environment, but also for identifying their responses to human-induced or climate- related changes in the system (González-Solís \& Shaffer 2009). Seabirds breeding in polar or temperate oceans may experience great seasonal changes in the marine environment (Ashmole 1971, Weimerskirch 2007). It is also virtually certain that seasonal changes in the marine environment affect the spatial and temporal distribution of marine organisms, including 
major fish or zooplankton that are prey for pelagic seabirds (Hunt 1990, Nihira 1996, Ballance et al. 2006, Iwahashi et al. 2006). Because pelagic seabirds may range widely over the ocean to reach distant foraging grounds, we expect that pelagic seabirds should track the spatial and temporal dynamics of their prey, induced by the seasonal changes in the marine environment.

Breeding seabirds, however, have some limitations in their foraging ranges because they have to return to the colony in order to engage in breeding activities, such as guarding nest sites, mating, incubating eggs, and provisioning chicks (Weimerskirch 2007). These breeding constraints may then lead to differences in a bird's selection of foraging area, depending upon the location of the colony in relation to productive feeding areas. Sex-related differences in flight morphology or reproductive roles may also constrain a bird's foraging range (Shaffer et al. 2001, Phillips et al. 2004b). For example, one sex may have higher wing loading and be better adapted for travelling over windy ocean areas, while individuals of another sex may assume a greater responsibility for incubating or chick-feeding and thus may have limited time available for foraging (Phillips et al. 2004b, Peck \& Congdon 2006). Nevertheless, the manner in which individual seabirds respond to seasonal changes in the marine environment has remained elusive, because, due to their high mobility, information on their at-sea distribution is generally lacking.

Streaked shearwaters Calonectris leucomelas breed on islands in east and southeast Asia, and major breeding populations exist in the regions of the Kuroshio, Oyashio, and the Kuroshio-Oyashio transition area in the North Pacific east of Japan (Oka 2004). The Kuroshio is the western boundary current of the North Pacific subtropical gyre that is characterized by warm and nutrient-poor surface waters, while the Oyashio is the western boundary current of the North Pacific subArctic gyre that is characterized by cold and nutrientrich surface waters (Kawai 1972, Qiu 2001, Sakurai 2007; Fig. 1). The area between the Kuroshio and Oyashio is known as the Kuroshio-Oyashio transition area, where the warm Kuroshio water and cold Oyashio water converge, generating a variety of complex hydrographic features (Kawai 1972, Olson 2001, Yasuda 2003). As a consequence of this highly dynamic ocean environment, the Kuroshio-Oyashio transition area represents one of the most productive zones in terms of carbon in the World Ocean (Kimura et al. 1997, Qiu 2001, Yasuda 2003, Sakurai 2007). Streaked shearwaters from both Sangan (SA) and Mikura (MK) Islands - located ca. $640 \mathrm{~km}$ apart, to the north and south of the Kuroshio-Oyashio transition area, respectively - forage in the northern part of the

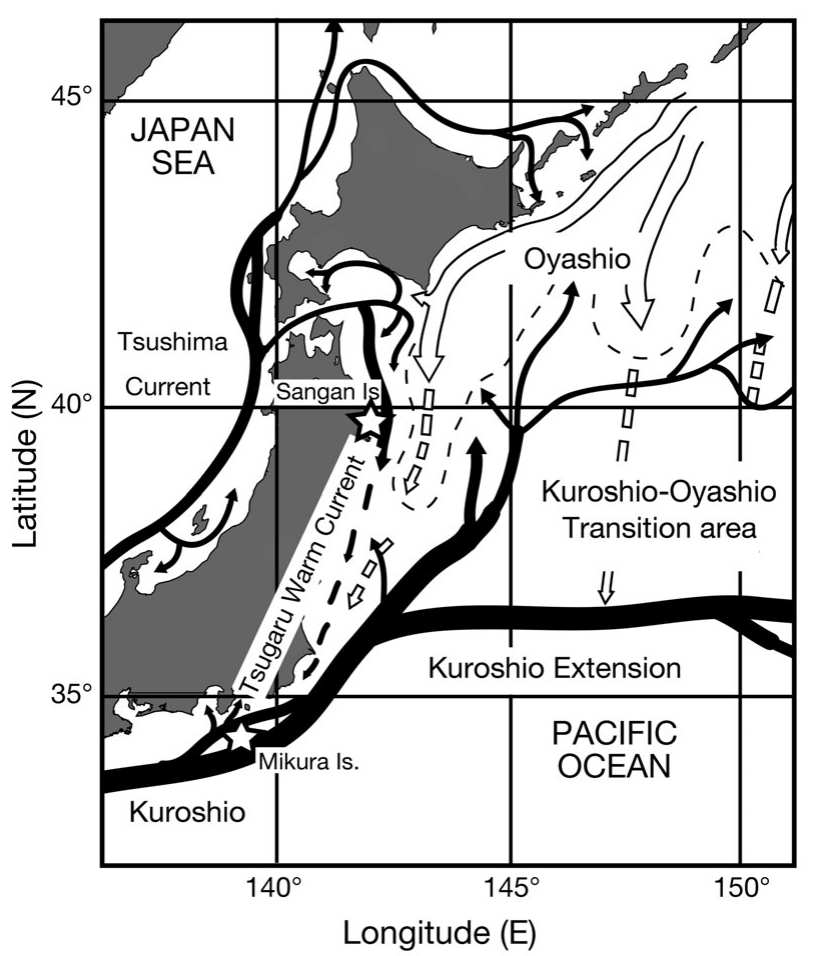

Fig. 1. Oceanographic features of the Northwestern Pacific along the eastern coast of Japan. Open arrows: Oyashio. Closed arrows: Kuroshio and Kuroshio Extension in the Pacific Ocean; Tsushima Warm Current and Tsugaru Warm Current in the Japan Sea and Pacific Ocean, respectively. Solid arrows: surface currents; dashed arrows: undercurrents.

Stars: study colonies on Sangan and Mikura islands

Kuroshio-Oyashio transition area and the Oyashio frontal zone during the chick-rearing period (Matsumoto 2008). However, this previous study (Matsumoto 2008) was conducted only over a short period (from late August to late September) during the chick-rearing period, and did not examine the foraging area of shearwaters in relation to the seasonal changes in their marine environment.

In the Northwestern Pacific, the position of the cold Oyashio fluctuates seasonally, shifting northward in summer and southward in winter, affecting seasurface temperature (SST) through warm/cold water advection (Kawai 1972, Qiu 2001). Thus, SST in the Northwestern Pacific reaches a minimum in March, and a maximum in August, showing one of the highest seasonal temperature changes (a range of $14^{\circ} \mathrm{C}$ ) in the world (Kawai 1972, Iwahashi et al. 2006). These seasonal temperature changes may affect the distribution and availability of zooplankton, which in turn should affect pelagic fishes (Odate 1994, Mihara 1998, Iwahashi et al. 2006), and thus any predators feeding upon them. We therefore hypothesize that streaked shearwaters may change their foraging areas seasonally, moving in association with the migration of their fish 
prey. In addition, we expect that patterns in the shift of foraging areas may differ according to sex as well as according to colony. Preferred foraging areas may be farther away from or closer to the colony depending on the time of the season and the location of the colony.

In the present study, we recorded the at-sea distribution of streaked shearwaters over 4 mo (April through July) using global location sensor loggers, and examined how seasonal changes in ocean conditions affected the foraging distribution of shearwaters. In addition, we examined inter-colony and sex-related differences in foraging area usage, the latter relating chiefly to nest attendance patterns.

\section{MATERIALS AND METHODS}

Study site. We conducted fieldwork on SA $\left(39^{\circ} 18^{\prime} \mathrm{N}\right.$, $141^{\circ} 58^{\prime} \mathrm{E}$, Iwate, Japan) located near the KuroshioOyashio transition area, and on MK $\left(33^{\circ} 52^{\prime} \mathrm{N}\right.$, $139^{\circ} 14^{\prime} \mathrm{E}$, Izu Islands, Japan) located in the Kuroshio area (Fig. 1). Approximately 109000 streaked shearwaters are estimated to breed on SA and from 17.5 to 35 million shearwaters on MK (Oka 2004, Matsumoto et al. 2007). Streaked shearwaters are monogamous seabirds. They return annually to their breeding colony beginning in late March, following their migration from southern wintering areas, and lay a single egg in mid-to-late June (Yoshida 1981, Yamamoto et al. 2010). The pre-laying period lasts ca. 3 mo, from April to June. The birds incubate eggs for ca. 51 d, and feed chicks for ca. 82 d (Yoshida 1981, Oka et al. 2002).

Logger deployment. We captured 48 chick-rearing birds (24 males and 24 females) at SA in midSeptember 2006 and 16 chick-rearing birds $(7$ males and 9 females) at MK in early October 2006, by hand, from nest burrows. A Global Location Sensor logger (GLS-Mk4, $25 \times 18 \times 7$ mm, 4.5 g, British Antarctic Survey) was attached to the tarsus of each bird using a plastic leg ring (Takahashi et al. 2008). The total mass of the GLS logger, including the leg ring, was $7 \mathrm{~g}$. This represents ca. $1.2 \%$ of the mean body mass of all study birds (mean $\pm \mathrm{SD}=570.4 \pm 74.9 \mathrm{~g}$ ) and ca. $1.6 \%$ of the body mass of the smallest bird (435 g). The attachment of GLS on a species from the same genus (the Cory's shearwater Calonectris diomedea) did not show any adverse effects on foraging behaviour or breeding success of these birds (Igual et al. 2005). We recaptured 38 of the 48 birds from SA in early August and late September 2007, and 7 of the 16 birds from MK in mid August 2007, either in their nest burrows or nearby. Three more MK birds were recaptured in early October 2008. Upon recovery, we removed the logger and plastic leg ring from each individual. We did not observe any injuries to their legs. To examine the effect of tag attachment on the birds' feeding success, we weighed the equipped and non-equipped birds at the time of recapture using a spring balance calibrated to the nearest $1 \mathrm{~g}$. We further determined the sex of all birds based on their vocalizations during handling. The calls of males are high-pitched whereas those of females are low-pitched (Arima \& Sugawa 2004).

Data analysis. The GLS loggers record time, light intensity, percentage of time immersed in seawater, and water temperature. The loggers were programmed to measure light levels at $60 \mathrm{~s}$ intervals, and to record the maximum value during each $10 \mathrm{~min}$ period. Time of immersion in seawater was measured every $3 \mathrm{~s}$ and data were compiled over each $10 \mathrm{~min}$ recording period. Water temperature was recorded only after continuous immersion for $20 \mathrm{~min}$, as the temperature sensors require $10 \mathrm{~min}$ to stabilize. We estimated the geographic location using the light data as follows: Sunset and sunrise times were estimated from thresholds in the light curves; we then derived the latitude based on day/night length, and longitude from time of local midday/midnight with respect to Greenwich Mean Time and Julian day, providing 2 locations per day (Hill 1994, Phillips et al. 2004a). Simultaneous deployment of geolocators with satellite tags (ARGOS Platform Terminal Transmitters) in polar and temperate regions have shown a mean location error of 186 km (Phillips et al. 2004a) and 202 km (Shaffer et al. 2005), respectively. Location errors were minimised by comparing the water temperature records with available satellite remotely sensed 8 d composite SST images from Aqua-MODIS (Moderate Resolution Images Spectroradiometer). This allowed us to estimate latitude on a daily basis, following the methods of Teo et al. (2004). During processing, any locations that were derived from light curves with obvious interruptions around sunset and sunrise, or that required unrealistic flight speeds (>35 $\mathrm{km} \mathrm{h}^{-1}$ sustained over a $48 \mathrm{~h}$ period) were identified and later excluded, following Takahashi et al. (2008).

For our analysis, we determined the breeding status of the birds either by direct observation of eggs or chicks at the time of recapture, or by examining whether the GLS data included repeated periods of darkness lasting longer than $4 \mathrm{~d}$, presumably representing time spent in incubation within nest burrows (see 'Results').

The foraging distribution of both male and female shearwaters from each colony was established by generating kernel density maps using the ESRI ${ }^{\circledR}$ ArcGIS Spatial Analyst Density tool with a cell size of $25 \mathrm{~km}$ and a search radius of $100 \mathrm{~km}$. A previous study had suggested that streaked shearwaters travel with a mean flight speed of $19.3 \mathrm{~km} \mathrm{~h}^{-1}$ (Matsumoto 2008). 
Thus, we defined the maximum potential daily foraging range of streaked shearwaters to be $<250 \mathrm{~km}$ from the island (Figs. $2 \& 3$ ). To compare the difference in atsea distribution between sexes as well as between months, we calculated the mean latitude, mean longitude, and mean distance from the breeding colony of the daily bird locations. We identified the day of return
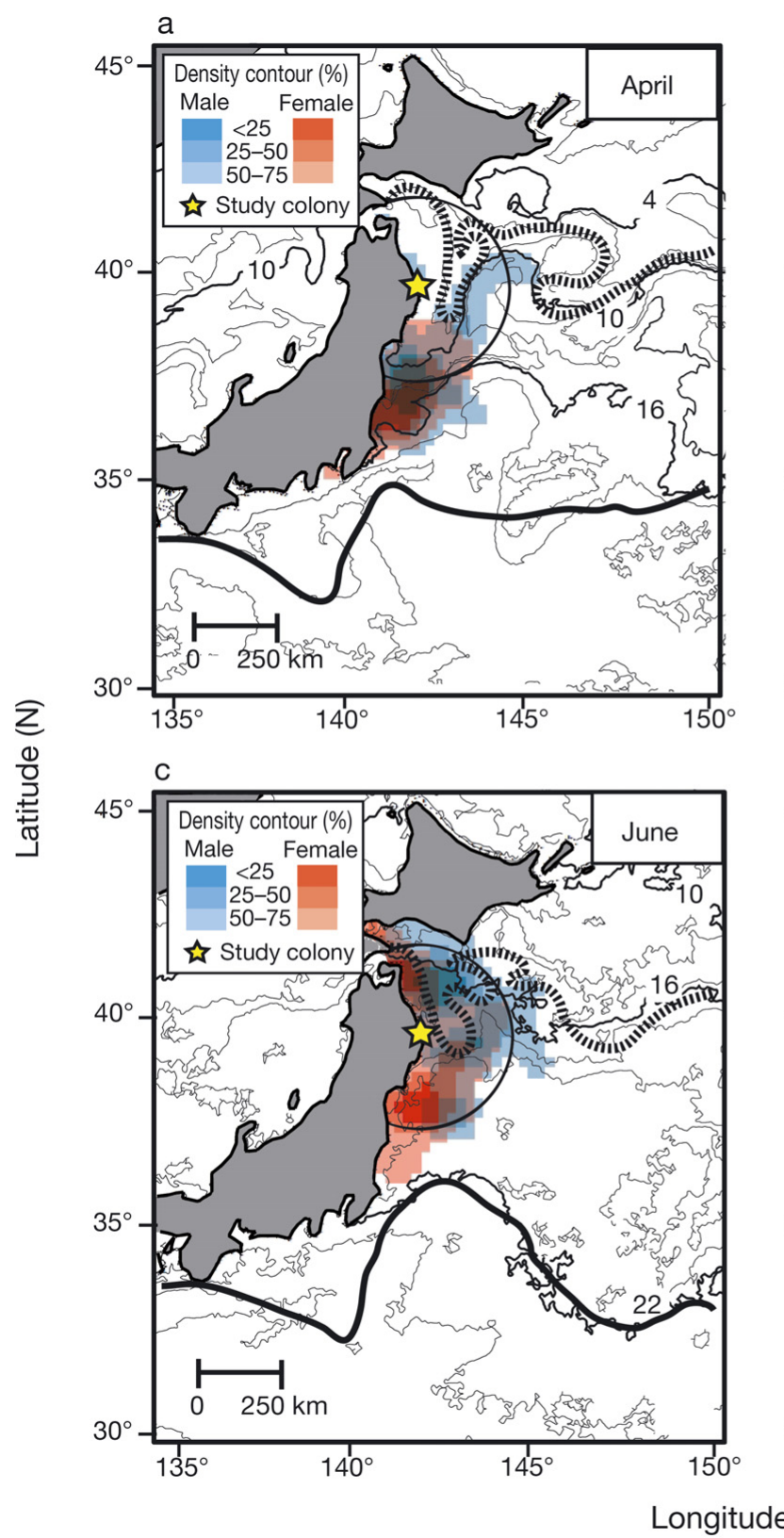

to the breeding colony using the light and immersion data (Rayner et al. 2008). Streaked shearwaters generally come ashore only at night. Most shearwaters land at the breeding colony after sunset, and depart from the colony before dawn (Yoshida 1981, T. Yamamoto pers. obs.). Periods spent in the nest burrow were also identified from the light and immersion data. Day and
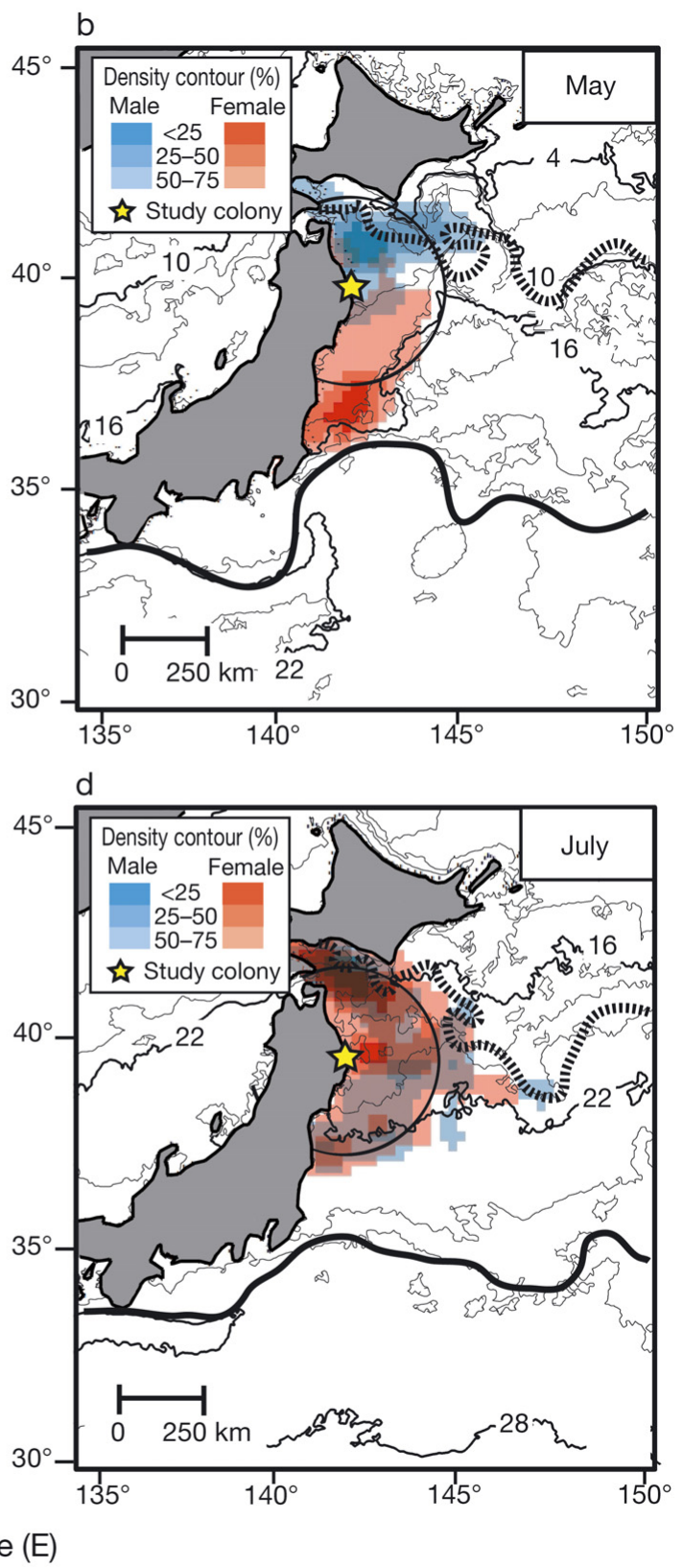

Fig. 2. Calonectris leucomelas. Kernel density distribution of breeding streaked shearwaters from Sangan Island in (a) April, (b) May, (c) June, and (d) July 2007, including (a-c) the pre-laying and (d) incubation periods. Density distributions are overlaid on the monthly composite sea surface temperature map (Aqua-MODIS) with contours at $2^{\circ} \mathrm{C}$ intervals (thin lines) and $6^{\circ} \mathrm{C}$ intervals (thick lines). The heavy solid black line indicates the approximate location of the Kuroshio (defined by the $14^{\circ} \mathrm{C}$ isotherm at $200 \mathrm{~m}$ depth), while the dashed line represents the approximate location of the Oyashio (defined by the $5^{\circ} \mathrm{C}$ isotherms at $100 \mathrm{~m}$ depth) from April to July in 2007, based on information supplied by the Japan Meteorological Agency (www.jma.go.jp). The approx. semicircle shows the potential maximum foraging range of streaked shearwaters for a daily round trip (250 km from the colony, based on information in Matsumoto 2008) 
night were identified using the light data, whilst visual examination of immersion data confirmed when birds returned to the colony, as immersion data were not recorded over a substantial period of the night. Therefore, we were able to calculate the foraging trip duration (at the accuracy level of $1 \mathrm{~d}$ ) and thus the attendance pattern at the colony.

Water temperatures recorded by the loggers were averaged daily to determine the SST of the foraging areas, because streaked shearwaters typically dive to $<3$ m (Matsumoto 2008). We then compared tempe- rature values with those obtained from monthly composite SST data (resolution of $9 \mathrm{~km}$, measured by Aqua-MODIS). We also obtained monthly composite chlorophyll a (chl a) concentrations (resolution of $9 \mathrm{~km}$, measured by Sea-viewing Wide Field-of-View Sensor (SeaWiFS) to examine productivity within the foraging areas. The oceanographic data were obtained from http://oceancolor.gsfc.nasa.gov, and extracted using the SeaWiFS Data Analysis System (SeaDAS, version 5.2). The locations of the Kuroshio front $\left(14^{\circ} \mathrm{C}\right.$ isotherm at $200 \mathrm{~m}$ depth) and Oyashio front $\left(5^{\circ} \mathrm{C}\right.$ isotherm at

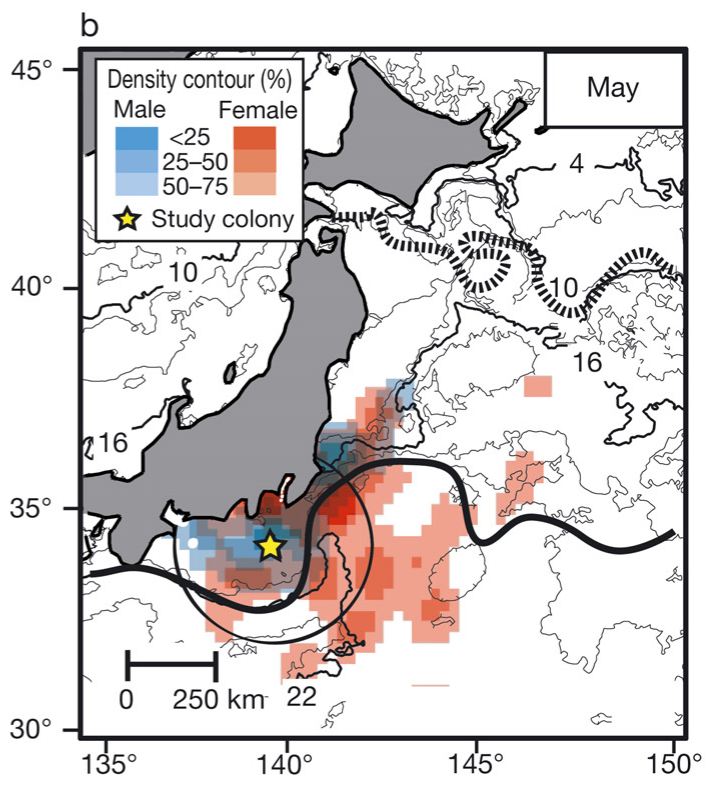

d

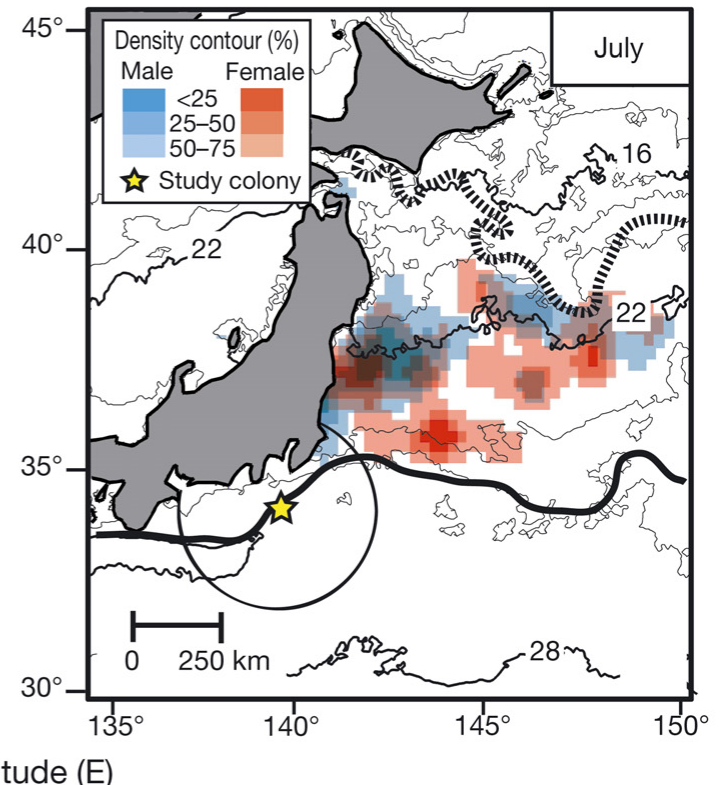

Fig. 3. Calonectris leucomelas. Kernel density distribution of breeding streaked shearwaters from Mikura Island in (a) April, (b) May, (c) June, and (d) July 2007, including (a-c) the pre-laying and (d) incubation periods. The background lines are the same as in Fig. 2 
$100 \mathrm{~m}$ depth, Kawai 1972) were obtained from information supplied by the Japan Meteorological Agency (www.jma.go.jp).

Statistical analysis. All statistical analyses were performed in R software, version 2.5.1 (R Development Core Team 2007). To test the differences in foraging behaviour between the sexes as well as from month to month, we fitted a Generalized Liner Mixed Model (GLMM) with either a Gaussian error distribution or a Poisson error distribution. Bird identity was set as a random factor in the models. The models with and without information on sex or month were compared using a likelihood ratio test. We also examined differences of daily bird locations (latitude, longitude and distance from the colony) between the sexes and by month, including individual bird identity as a random factor. The differences in attendance patterns and in chl a concentration within core foraging areas between the sexes were compared using ANOVA. The percentages of nights that individuals appeared at the breeding colony were arcsine-transformed prior to analysis. We used R package lme4 and function lmer for the linear models. Values are presented as mean \pm SD. Statistical significance was set at $<0.05$.

\section{RESULTS}

Data from the recovered 48 GLS loggers (38 from SA and 10 from $\mathrm{MK}$ ) were successfully downloaded. However, 8 loggers from SA had recording errors and the data were partially or completely unusable. For our analysis of data from SA birds, we used 21 breeding birds (9 males and 12 females) and 9 non-breeding birds (4 males and 5 females). For our analysis of data from MK birds, we used 8 breeding birds (4 males and 4 females) and 2 non-breeding birds ( 2 males). There was no difference in body mass between birds with and without GLS loggers at the time of recapture at SA
(Yamamoto et al. 2008) or MK (2-way ANOVA: sex: $F_{1,18}=14.92, \mathrm{p}<0.01 ;$ equipment: $\left.F_{1,18}=0.23, \mathrm{p}=0.64\right)$.

\section{Foraging areas}

Female streaked shearwaters from SA changed their major foraging areas, moving from south to north of the breeding colony along the coast in the KuroshioOyashio transition area as the season progressed (from month to month, likelihood ratio test, all $\mathrm{p}<0.001$; Fig. 2, Table 1). Males from SA also changed their foraging areas, moving northward from April to May, and southward from June to July (likelihood ratio test, p < 0.01 for April vs. May, June vs. July; Fig. 2, Table 1). Thus males, unlike females, did not show a steady northward movement in their foraging areas from April to July. Core foraging areas (50\% kernel area) overlapped to a relatively high degree between the sexes in April and July, but less so in June, and they were completely segregated in May (Table 2). The daily mean distance from the colony for bird location was shorter for males than females only in May (likelihood ratio test, $\mathrm{p}<0.01$; Table 1 ).

Female streaked shearwaters from MK changed their major foraging areas by moving eastward from April to June along the Kuroshio and Kuroshio Extension (from month to month, likelihood ratio test, p < 0.001 for April vs. May, and May vs. June) and northward from June to July (likelihood ratio test, $\mathrm{p}<0.001$ for June vs. July; Fig. 3, Table 1). Males from MK changed their foraging areas by moving northward from April to July along the coast (likelihood ratio test, all $\mathrm{p}<0.05$ ), and also eastward from May to July (likelihood ratio test, $\mathrm{p}<0.05$ for May vs. June, and June vs. July; Fig. 3, Table 1). Core foraging areas overlapped between the sexes from April to July, and the proportion of overlap in the foraging areas was larger for males (from 34.7 to $62.1 \%$ ) than for females (from 9.0 to

Table 1. Calonectris leucomelas. Summary of the mean latitude, mean longitude, and mean distance from the colony for daily bird locations at Sangan Island (9 males, 12 females) and Mikura Island (4 males, 4 females) from April to July 2007. Values calculated using individual bird data. Distance is presented as mean $\pm \mathrm{SD}$

\begin{tabular}{|c|c|c|c|c|c|c|c|}
\hline $\begin{array}{l}\text { Breeding } \\
\text { colony }\end{array}$ & Month & Latitude (N) & $\begin{array}{c}\text { Male } \\
\text { Longitude (E) }\end{array}$ & $\overline{\text { Distance }(\mathrm{km})}$ & Latitude (N) & $\begin{array}{c}\text { Female } \\
\text { Longitude (E) }\end{array}$ & Distance $(\mathrm{km})$ \\
\hline \multirow[t]{4}{*}{ Sangan Island } & April & $37^{\circ} 48^{\prime}$ & $141^{\circ} 57^{\prime}$ & $298 \pm 38$ & $36^{\circ} 53^{\prime}$ & $141^{\circ} 46^{\prime}$ & $335 \pm 71$ \\
\hline & May & $40^{\circ} 09^{\prime}$ & $142^{\circ} 23^{\prime}$ & $243 \pm 38$ & $37^{\circ} 38^{\prime}$ & $142^{\circ} 04^{\prime}$ & $319 \pm 72$ \\
\hline & June & $40^{\circ} 11^{\prime}$ & $142^{\circ} 39^{\prime}$ & $249 \pm 29$ & $39^{\circ} 06^{\prime}$ & $141^{\circ} 38^{\prime}$ & $277 \pm 86$ \\
\hline & July & $39^{\circ} 37^{\prime}$ & $142^{\circ} 59^{\prime}$ & $284 \pm 50$ & $39^{\circ} 41^{\prime}$ & $143^{\circ} 02^{\prime}$ & $261 \pm 44$ \\
\hline \multirow{4}{*}{ Mikura Island } & April & $34^{\circ} 14^{\prime}$ & $140^{\circ} 06^{\prime}$ & $287 \pm 53$ & $33^{\circ} 25^{\prime}$ & $139^{\circ} 55^{\prime}$ & $492 \pm 219$ \\
\hline & May & $34^{\circ} 51^{\prime}$ & $140^{\circ} 07^{\prime}$ & $244 \pm 16$ & $33^{\circ} 44^{\prime}$ & $142^{\circ} 10^{\prime}$ & $363 \pm 39$ \\
\hline & June & $35^{\circ} 29^{\prime}$ & $141^{\circ} 13^{\prime}$ & $350 \pm 93$ & $34^{\circ} 15^{\prime}$ & $144^{\circ} 10^{\prime}$ & $496 \pm 60$ \\
\hline & July & $37^{\circ} 16^{\prime}$ & $143^{\circ} 21^{\prime}$ & $589 \pm 138$ & $36^{\circ} 41^{\prime}$ & $144^{\circ} 31^{\prime}$ & $641 \pm 130$ \\
\hline
\end{tabular}


$36.3 \%$; Table 2). The daily mean distance from the colony for bird location differed between the sexes in May and June (likelihood ratio test, both $\mathrm{p}<$ 0.05; Table 1).

Females from SA generally appeared to occupy areas with a restricted range of SSTs (from 14 to $17^{\circ} \mathrm{C}$ ) from April to July as the birds changed their foraging areas (Fig. 4a-d). In contrast, males of SA tended to use the areas around the colony, within their daily foraging range from May to July, without regard to SST, though they generally used areas cooler than those immediately around the colony. In May and June, males used the areas with SSTs significantly lower than those of females (likelihood ratio test, both $\mathrm{p}<0.05$ ). At SA, chlorophyll a concentration within the core foraging area was higher for females than for males in April and May, but not in June and July (Table 3). Females from MK also appeared to use areas with a restricted range of SSTs (from 20 to $22^{\circ} \mathrm{C}$ ) from April to July (Fig. 4e-h). Males from MK frequently used areas around the colony, or areas cooler than those around the colony. Males and females used different SST areas in May and June (likelihood ratio test, both $\mathrm{p}<0.05$ ), but not in April and July. From April to June, females used areas with lower chlorophyll a concentrations than those used by males, but in July, areas used by each sex had similar chlorophyll a concentrations (Table 3).

Core foraging areas overlapped slightly between the colonies in April, May, and July, but were completely segregated in June (Table 2).

\section{Foraging trip durations and colony attendance patterns}

From April to June, females from SA undertook foraging trips that were significantly longer than those undertaken by males (likelihood ratio test, all $\mathrm{p}<0.01$ ) (Fig. 5a-d). Similarly, females from MK showed longer foraging trips than males from April to June (all p < 0.05) (Fig. 5e-h). In July, foraging trip duration was similar for both sexes, although males of SA took significantly longer trips than females ( $p<0.05)$.

In June, all females from both colonies performed one long foraging trip $(15.5 \pm 2.3 \mathrm{~d}$ at $\mathrm{SA}$, and $17.0 \pm$ $2.9 \mathrm{~d}$ at $\mathrm{MK}_{\mathrm{i}}$ Fig. 5c,g). This behaviour is presumably related to the pre-laying exodus, during which females are thought to accumulate resources required to produce an egg (Warham 1990). In contrast, the longest foraging trips for males from both colonies in June were shorter $(5.6 \pm 2.7 \mathrm{~d}$ at $\mathrm{SA}$, and $6.8 \pm 4.5 \mathrm{~d}$ at $\mathrm{MK})$ than those of females. At SA, females started their longest foraging trips on 8 June $\pm 3.5 \mathrm{~d}$ (range from 1 to 14 June), and at MK on 4 June $\pm 3.0 \mathrm{~d}$ (range from 1 to 8 June). The SA females returned to the colony on 22 June $\pm 2.5 \mathrm{~d}$ (range from 18 to 27 June), and the MK females on 20 June $\pm 1.5 \mathrm{~d}$ (range from 18 to 21 June).

Shearwaters from both colonies showed different attendance patterns depending upon gender. Between April and June, males returned frequently to the breeding colony, while females returned to the colony much less frequently. In July, however, both sexes returned to the colony equally (Table 4).

Between April and June, both sexes were often present at the colony for a single night (at SA: males $1.4 \pm$ $1.0 \mathrm{~d}$, and females $1.6 \pm 1.1 \mathrm{~d}$; at MK: males $1.4 \pm 1.0 \mathrm{~d}$, and females $1.9 \pm 1.3 \mathrm{~d}$ ), while birds stayed continuously in the burrows for approx. $1 \mathrm{wk}$ in July (at SA: males $6.7 \pm 2.5$ nights, and females $6.0 \pm 3.3$ nights; at MK: males $7.3 \pm 3.7$ nights, and females $6.7 \pm 3.9$ nights), presumably for incubation routines. The long attendance immediately after the long absence of females at the colony in late June indicates that, at SA, they probably laid their single egg on 23 June $\pm 2.6 \mathrm{~d}$ (range from 18 to 28 June), and at MK, on 21 June \pm $1.3 \mathrm{~d}$ (range from 19 to 22 June).

\section{Behaviour of non-breeding birds}

In April, core foraging areas (50\% of kernel density) of non-breeding birds ( 4 males and 5 females) from SA overlapped with those of breeding males from SA by $67.5 \%$, and with those of breeding females from SA by $63.7 \%$; in May, by 50.9 and $4.6 \%$, respectively; in June, by 35.1 and $33.9 \%$, respectively; and in July, by 60.8 and $71.9 \%$, respectively. In April, core foraging areas of non-breeding birds (2 males) from MK overlapped with those of breeding males from MK by $40.9 \%$ and with those of breeding females from MK by $52.4 \%$; in May, by 71.4 and $60.7 \%$, respectively; in June, by 41.2 and $23.3 \%$, respectively; and in July by 16.2 and $27.1 \%$, respectively. 

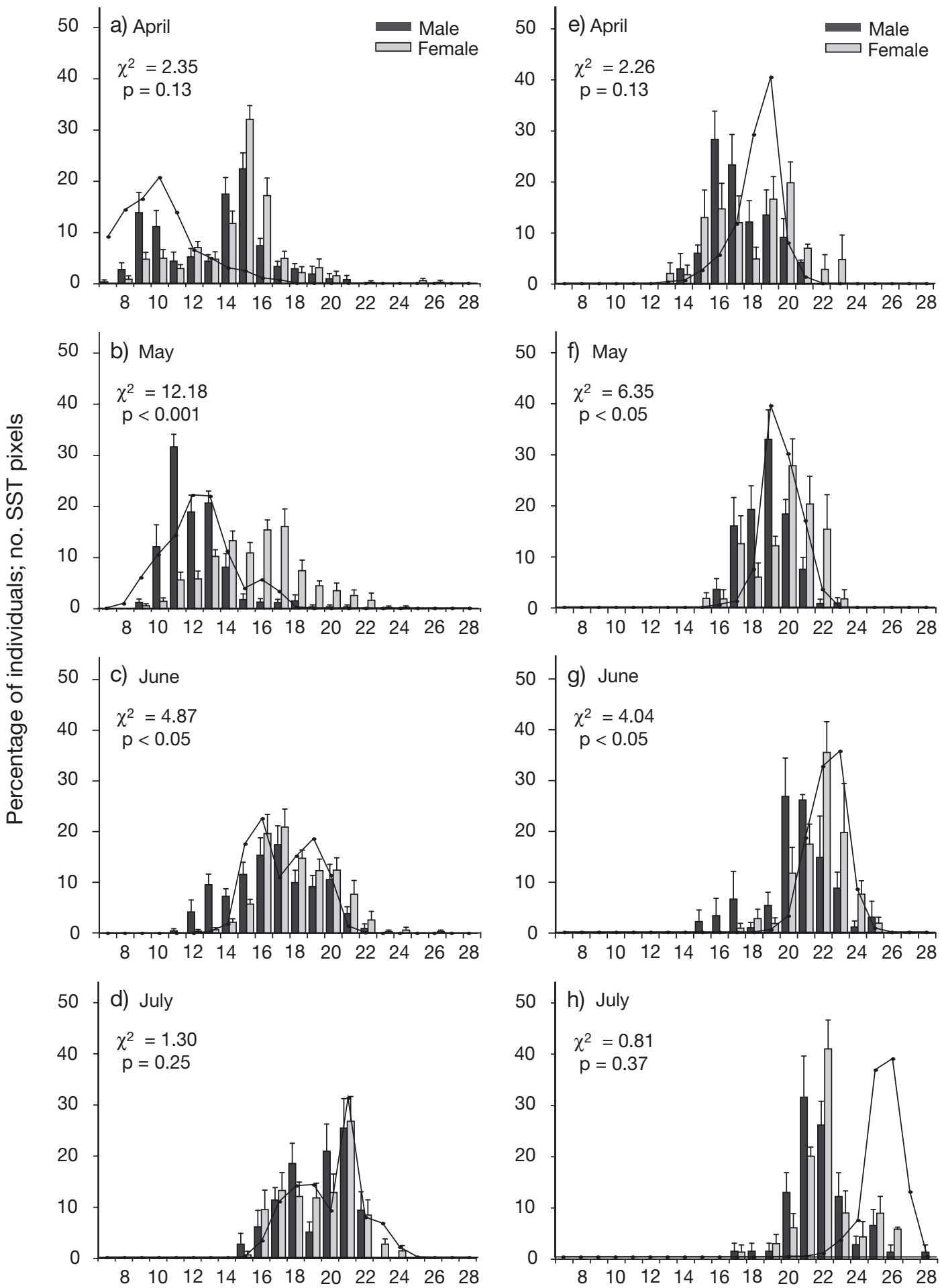

Water temperature $\left({ }^{\circ} \mathrm{C}\right)$

Fig. 4. Calonectris leucomelas. Daily averaged water temperatures that individuals experienced during foraging trips; (a-d) birds from Sangan Island, and (e-h) birds from Mikura Island in April (a,e), May (b,f), June (c,g), and July (d,h) 2007. Data are presented as mean $\pm \mathrm{SE}$, calculated using individual bird data. Number of sea surface temperature (SST) pixels within the potential daily foraging range of birds (within $250 \mathrm{~km}$ from the colony) obtained from satellite data are also shown as line graphs 
Table 3. Calonectris leucomelas. Chlorophyll a concentration (mean \pm SD) within the core foraging area $(50 \%$ kernel density distribution) at Sangan and Mikura islands from April to July 2007. Significant differences were tested using ANOVA

\begin{tabular}{|c|c|c|c|c|c|c|c|c|c|c|}
\hline \multirow{2}{*}{ Month } & \multicolumn{2}{|c|}{ - Sangan Island — } & \multirow{2}{*}{$\mathrm{df}$} & \multirow[t]{2}{*}{$F$} & \multirow[t]{2}{*}{$\mathrm{p}$} & \multicolumn{2}{|c|}{ — Mikura Island — } & \multirow{2}{*}{$\mathrm{df}$} & \multirow{2}{*}{$F$} & \multirow{2}{*}{$\mathrm{p}$} \\
\hline & Male & Female & & & & Male & Female & & & \\
\hline April & $0.92 \pm 0.42$ & $1.02 \pm 0.52$ & 1,879 & 11.26 & $<0.01$ & $1.30 \pm 1.79$ & $0.64 \pm 0.68$ & 1,1052 & 52.82 & $<0.01$ \\
\hline May & $1.25 \pm 0.33$ & $1.49 \pm 0.45$ & 1,749 & 68.96 & $<0.01$ & $0.71 \pm 0.52$ & $0.63 \pm 0.74$ & 1,1607 & 6.55 & $<0.05$ \\
\hline June & $0.55 \pm 0.25$ & $0.53 \pm 0.16$ & 1,1297 & 3.06 & 0.08 & $0.50 \pm 0.44$ & $0.25 \pm 0.15$ & 1,1341 & 225.95 & $<0.01$ \\
\hline July & $0.39 \pm 0.17$ & $0.36 \pm 0.14$ & 1,1367 & 15.96 & $<0.01$ & $0.24 \pm 0.10$ & $0.23 \pm 0.07$ & 1,1289 & 3.82 & 0.05 \\
\hline
\end{tabular}

At $\mathrm{SA}$, non-breeding males tended to return to the breeding colony less frequently (from 34.7 to $44.4 \%$ of the nighttime from April to July) than breeding males (ANOVA, April: $F_{1,11}=$ 9.60, p < 0.05; May: $F_{1,11}=14.80, \mathrm{p}<$ 0.01; June: $F_{1,11}=4.15, \mathrm{p}=0.07$; and July: $F_{1,11}=4.80, \mathrm{p}=0.05$; Table 4 ). Non-breeding females of SA returned to the colony at a similar frequency to breeding females in April, May, and July (from 45.8 to $60.6 \%$ of the nighttime), but returned more frequently (60.0\% of the nighttime) in June (ANOVA, April: $F_{1,11}=1.54, \mathrm{p}=0.23$; May: $F_{1,11}=4.22, \mathrm{p}=0.06$; June: $F_{1,11}=$ 57.93, $\mathrm{p}<0.01$; and July: $\left.F_{1,11}=0.11, \mathrm{p}=0.74\right)$. In June, non-breeding females at SA showed only a relatively short absence from the colony $(7.8 \pm 4.3 \mathrm{~d})$, unlike breeding females of the same colony, which showed a long pre-laying exodus (Fig. 5c,g). Similarly, at MK, non-breeding males tended to return to the breeding colony less frequently (from 37.1 to $60.0 \%$ of the nighttime from April to July), than breeding males (Table 4). We have no data for non-breeding females at MK.

\section{DISCUSSION}

\section{Seasonal changes in foraging area}

Information on the diet of streaked shearwaters indicates that they predominantly feed on pelagic fish in the Northwestern Pacific; principally Japanese anchovy Engraulis japonicas $(65.1 \%$ at SA and from 23.1 to $50.0 \%$ at $\mathrm{MK}$, by percentage frequency of occurrence), with the rest of the diet including Pacific saury Cololabis saira $(9.3 \%$ at SA and from 3.8 to $18.8 \%$ at MK), flying fish Cypselurus hiraii (4.7\% at SA and from 6.3 to $18.2 \%$ at MK), and squid Todarodes pacificus $(2.3 \%$ at SA and from 18.2 to $23.1 \%$ at MK) (K. Matsumoto unpubl. data). Although the prey species of streaked shearwaters during the pre-laying and incubation periods has not been reported, streaked shearwaters are often observed aggregating over pelagic fish schools at sea (Nakamura 1974, Takahashi 2000, Ogi \& Ryu 2001).

Streaked shearwaters from both colonies studied changed their major foraging areas, moving northward in association with seasonal changes in SST (Figs. 2 \& 3). The northward seasonal movements appeared to match the seasonal development of oceanographic processes in the Kuroshio-Oyashio region. Zooplankton biomass is generally low in the warm Kuroshio water, except along the frontal or coastal regions, while primary productivity and zooplankton biomass are generally high in the cold Oyashio water (Odate 1994, Kasai et al. 2001, Sakurai 2007). For this reason, the Oyashio is the main feeding grounds for many pelagic fish species (Odate 1994, Sakurai 2007). However, the distribution of these pelagic fishes is directly affected by water temperature (Oozeki et al. 2007, Takasuka et al. 2008b). Water temperatures of the Kuroshio-Oyashio region increase from spring to summer by solar heating and by the seasonal decrease of cold water transport of the Oyashio current (Kawai 1972, Qiu 2001). Thus, pelagic fishes such as Japanese anchovy, Pacific saury, and Japanese sardine, in association with increasing SST, migrate northward in spring and summer to feed or spawn in the productive KuroshioOyashio transition area (Odate 1994, Mihara 1998, 
Sangan Island
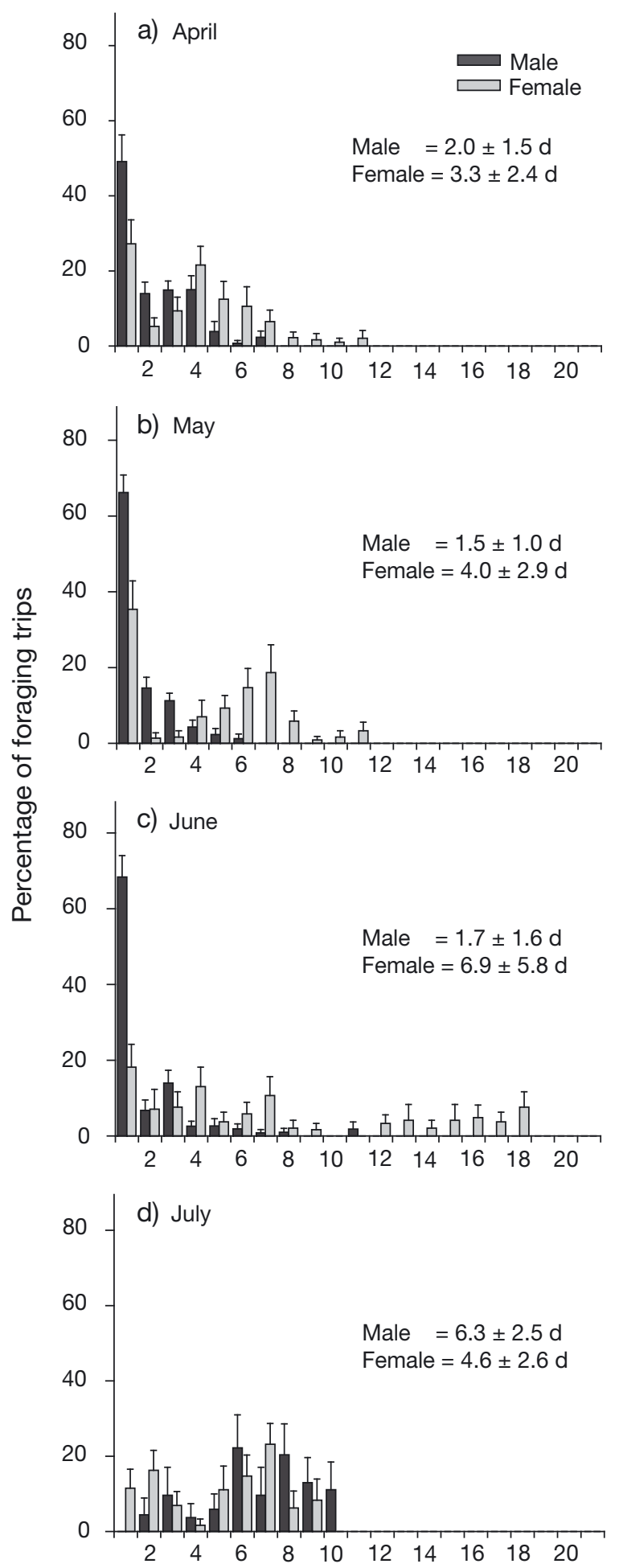

Mikura Island
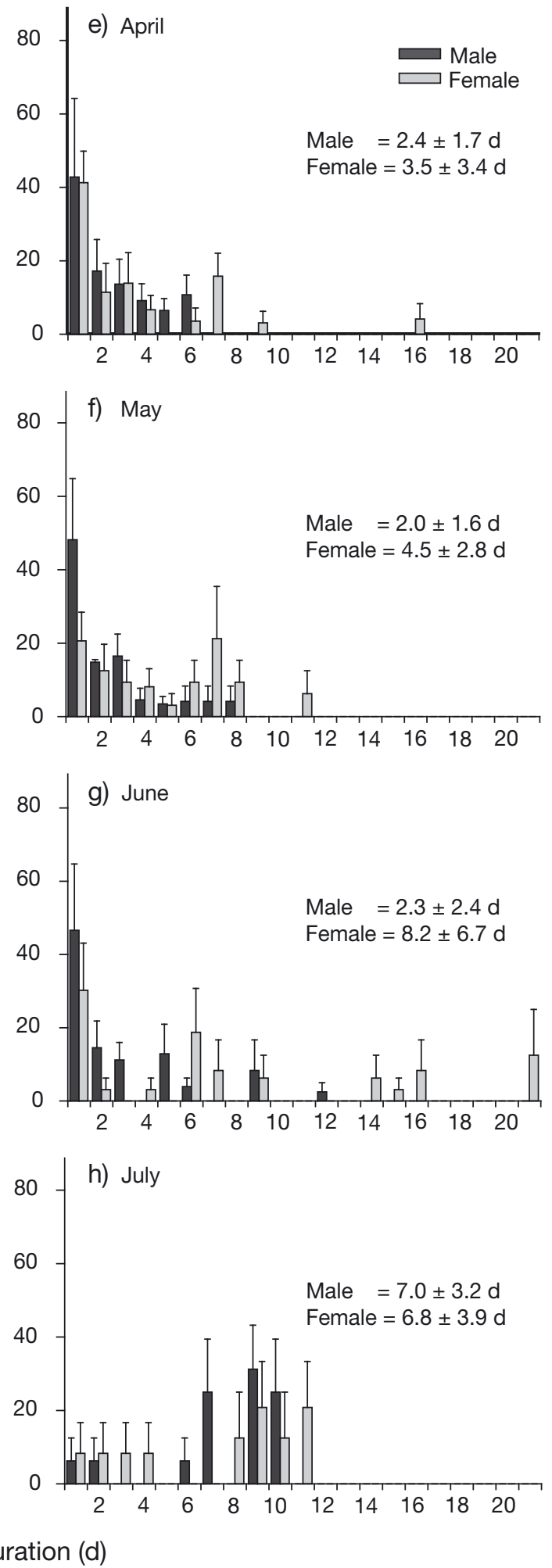

Fig. 5. Calonectris leucomelas. Sex-related differences in foraging trip duration undertaken by individual breeding streaked shearwaters from Sangan Island (a-d), and Mikura Island (e-h) from April $(\mathrm{a}, \mathrm{e})$, May $(\mathrm{b}, \mathrm{f}), \mathrm{June}(\mathrm{c}, \mathrm{g})$, and July (d,h) 2007. Data are presented as mean \pm SE, calculated using individual bird data. Grand mean \pm SD is also shown 
Sugisaki \& Kurita 2004, Iwahashi et al. 2006, Sakurai 2007). Predators of these pelagic fishes, such as tunas and seabirds, are also known to migrate into this area in the summer (Shiomi \& Ogi 1992, Nihira 1996, Kitagawa et al. 2004).

Although streaked shearwaters broadly showed the northward shift of their foraging areas, the pattern of seasonal changes differed between the colonies depending upon the location of accessible productive areas. Shearwaters from SA changed their foraging areas along the coastal areas of the Kuroshio-Oyashio transition (Fig. 2), while shearwaters from MK changed their foraging areas along the Kuroshio and Kuroshio Extension (Fig. 3). In coastal areas of the Kuroshio-Oyashio transition, Kuroshio, Oyashio, and Tsugaru Warm Current interact and enhance primary productivity (Hanawa \& Mitsudera 1987, Kasai et al. 2002, Suryan et al. 2006), supporting high fish abundance (Hayasi 1966, Nakata et al. 2000, Takasuka et al. 2008a). The eastward-flowing Kuroshio and Kuroshio Extension regions, on the other hand, where shearwaters from MK feed, support major spawning and nursery grounds for various pelagic fishes, such as anchovy and sardine (Aoki \& Miyashita 2000, Kasai et al. 2002, Komatsu et al. 2002, Sassa et al. 2004, Takahashi \& Watanabe 2004). Frontal cyclonic eddies in this region enhance primary and secondary productivity (Kimura et al. 1997, 2000, Qiu 2001), supporting a range of predators, including, tunas, turtles, and seabirds (Kitagawa et al. 2004, Takasuka et al. 2004, Polovina et al. 2006, Suryan et al. 2006, Shaffer et al. 2006).

Core foraging areas overlapped only slightly between the colonies (Table 2), and these overlapping areas were located in the coastal water (Figs. $2 \& 3$ ). Colony-specific foraging habitat has been reported in a variety of seabird species (Weimerskirch et al. 1988, Wanless \& Harris 1993, Grémillet et al. 2004). Seabirds from neighbouring colonies tend to feed in nonoverlapping zones to minimise intra-specific competition for food resources, with the zone of feeding habitat typically closer to a focal colony than any of the neighbouring colonies in the hinterland (Cairns 1989). Females of MK often used offshore areas along the Kuroshio and Kuroshio Extension, where productivity is locally enhanced by frontal cyclonic eddies in lowproductivity Kuroshio water, and where many predators congregate to feed (Kimura et al. 1997, 2000, Kitagawa et al. 2004, Polovina et al. 2006). Waters of the Kuroshio and Kuroshio Extension are much closer to MK than to SA (Fig. 1), hence females of MK are able to reach and forage in these regions in addition to coastal areas during their pre-laying period. As MK contains the largest breeding colony (from 17.5 to 35 million birds) of this species (Oka 2004), the broad range of foraging areas for females from MK may pos- sibly relate to the avoidance of intra-specific resource competition (Lewis et al. 2001).

In the Northwestern Pacific, other shearwater species (such as short-tailed Puffinus griseus and sooty shearwaters $P$. tenuirostris) also occur during the boreal summer whilst over-wintering (Warham 1996, Shaffer et al. 2006). Short-tailed shearwaters feed mainly on euphausiids (Ogi et al. 1980), and sooty shearwaters predominantly feed on pelagic fish, such as Japanese sardine and Pacific saury (Shiomi \& Ogi 1992). In spring, short-tailed shearwaters migrate north to northern Oyashio areas; sooty shearwaters also migrate northwards, congregating over waters of 9 to $13^{\circ} \mathrm{C}$ (Ogi 1984, Shiomi \& Ogi 1992, Ito 2002). These northward migrations have also been considered to coincide with the distribution and availability of prey (Shiomi \& Ogi 1992, Warham 1996, Ito 2002).

\section{Sex-related differences}

Our results showed that foraging trip duration, foraging areas, and attendance patterns differed between sexes at both colonies from April to June (pre-laying period) but not in July (incubation period).

Male streaked shearwaters had shorter foraging trips than females during the pre-laying period, but not during the incubation period (Fig. 5). During the pre-laying period, time available for foraging may be limited for males by the need to attend the breeding colony (Table 4), which may limit the potential foraging distance from the colony. In contrast, more foraging time should be available for females at this time. In this respect, we might expect females to forage in more productive areas than males during the prelaying period. In both colonies, however, foraging areas for females did not always coincide with areas of higher chl a concentration (Table 3 ). This could be explained, in part, by the time lags between increased primary productivity and associated increase in the availability of shearwater prey (Odate 1994, Suryan et al. 2006, Grémillet et al. 2008). Furthermore, the distribution of pelagic fishes that shearwaters mainly feed on is affected directly by SST (Oozeki et al. 2007, Takasuka et al. 2008a,b). For example, Japanese anchovy appear to prefer particular ranges of SST (from 12 to $18^{\circ} \mathrm{C}$ for feeding, and from 20 to $22^{\circ} \mathrm{C}$ for spawning; Tsuruta \& Takahashi 1997, Mihara 1998, Takasuka et al. 2008b). In fact, female streaked shearwaters from both colonies appeared to favour relatively narrow ranges of SST through several months, as compared to males (Fig. 4). This may suggest that female streaked shearwaters feed on those migratory fish, distributed in particular SST zones, in the Northwestern Pacific. 
In June, all females as well as some males undertook longer foraging trips (Fig. 5). We consider these trips to be related to the pre-laying exodus. The pre-laying exodus is seen among most Procellariiformes, and is thought to occur so that females can gather the necessary resources needed to produce an egg (Warham 1990). In fact, in June, non-breeding females showed shorter absences from the colony than breeding females. The periods that streaked shearwaters were absent were similar to that of the closely related Cory's shearwater (females: $19 \mathrm{~d}$, males: $8 \mathrm{~d}$; Jouanin et al. 2001).

Sex-related differences in foraging areas are commonly observed among flying seabirds, and have been attributed to the differences in flight morphology or to differing reproductive roles between the sexes (González-Solís et al. 2000, Shaffer et al. 2001, Lewis et al. 2002, Phillips et al. 2004b). Although male streaked shearwaters are 1.2 times heavier and have larger bodies than females (Arima \& Sugawa 2004, Ochi et al. 2010), foraging areas differed between the sexes only during pre-laying and not during incubation. Thus, we suggest that the sex-related preference for foraging areas is related to the difference in reproductive roles, rather than the difference in body size, as nest attendance patterns also differed accordingly between sexes.

Males returned to the breeding colony more frequently than females during the pre-laying period (Table 4), possibly to prevent burrows from being occupied by other prospecting birds (Burger 1981, Hatch 1987). Aggressive territorial defence is observed in streaked shearwaters at the colony from March to May, although the sex of birds conducting the defence was undetermined (Yoshida 1981). Males may also be engaged in extra-pair copulations, or, conversely, in guarding a mate from being copulated with other prospectors (Hatch 1987). Extra-pair paternity rate in streaked shearwaters breeding on SA was about $30 \%$ (K. Watanabe unpubl data), and frequent extra-pair copulation attempts occur between mid May and mid June at the breeding colony (Yoshida 1981).

Non-breeding males returned to the colony less frequently than breeding males. Therefore, the foraging ranges of non-breeding birds may not be constrained by breeding duties as much as the ranges of breeders. However, the foraging areas of non-breeding birds unexpectedly overlapped with those of breeding males rather than those of breeding females. We have no clear explanation for those patterns, but it may relate to the fact that we were not able to distinguish whether non-breeding birds did not attempt to breed in the study year, or just failed in the early breeding stage. A previous study has also shown that non-breeding birds do not always behave differently from breeding birds (marbled murrelets Brachyramphus marmoratus; Hébert \& Golightly 2008). Although the foraging behaviour of non-breeding birds has been much less reported than that of breeding birds, populations do include a certain proportion of non-breeding birds (Warham 1990). Thus it is important to examine the foraging behaviour of non-breeding birds in relation to oceanographic features for understanding the ecology of a given species.

\section{CONCLUSION}

Streaked shearwaters changed their foraging areas, moving northwards from April to July as SST increased seasonally in the Northwestern Pacific. The northward shift of foraging areas appeared to match the general northward movement of pelagic fish from spring to summer reported in this region. However, the patterns of change in foraging areas differed between the colonies as well as between the sexes. Shearwaters from SA foraged along the coastal areas of the Kuroshio-Oyashio transition, while shearwaters from MK foraged in areas along the Kuroshio and Kuroshio Extension. From April to June (pre-laying period), males took shorter foraging trips and foraged in areas closer to the colony than females did, possibly because males needed to return to the breeding colony more frequently to defend their nests or mates. Thus, the environmental responses of streaked shearwaters would be limited by colony location and sex-specific breeding constraints. These results imply that the effects of climate-related changes in the Northwestern Pacific (Chiba et al. 2006) may have a differential impact on shearwaters from different colonies and of different sexes.

Acknowledgements. We are very grateful to the late S. Kurimoto and N. Miura for logistical support, and to the staff of the International Coastal Research Center, Atmosphere and Ocean Research Institute, University of Tokyo, for their kind support in the field. We also thank S. Watanabe, K. Watanabe, Y. Hirose, T. Fukuda, S. Sasaki, K. Tamori, D. Ochi, and S. Hirose for their assistance in the field. Our thanks to K. Matsumoto for allowing us to access dietary data of streaked shearwaters, to D. Kawai for help with data analysis, to V. Afanasyev and J. Fox for developing the geolocators, and to 3 anonymous reviewers for critical comments to improve our manuscript. This work was supported by JSPS research grants (19651100 to A.T. and 19255001 to K.S.) and by a Grant-in-Aid for Scientific Research (Special Promotion) of the Ministry of Education, Culture, Sports, Science and Technology-Japan to N.O. of Yamashina Institute for Ornithology. All animal experiments were approved by the Animal Experimental Committee of the University of Tokyo and conducted in accordance with the Guidelines for the Care of Experimental Animals. This work was conducted with permits from the Ministry of the Environment and the Agency for Cultural Affairs. 


\section{LITERATURE CITED}

Aoki I, Miyashita K (2000) Dispersal of larvae and juveniles of Japanese anchovy Engraulis japonicus in the Kuroshio Extension and Kuroshio-Oyashio transition regions, western North Pacific Ocean. Fish Res 49:155-164

> Arima H, Sugawa H (2004) Correlation between the pitch of calls and external measurements of Streaked Shearwaters Calonectris leucomelas breeding on Kanmuri Island. Jpn J Ornithol 53:40-44

Ashmole NP (1971) Seabird ecology and the marine environment. In: Farner DS, King JR (eds) Avian biology, Vol 1. Academic Press, New York, NY, p 223-286

Ballance LT, Pitman RL, Fiedler PC (2006) Oceanographic influences on seabirds and cetaceans of the eastern tropical Pacific: a review. Prog Oceanogr 69:360-390

Burger J (1981) Sexual differences in parental activities of breeding black skimmers. Am Nat 117:975-984

Cairns DK (1989) The regulation of seabird colony size: a hinterland model. Am Nat 134:141-146

> Chiba S, Tadokoro K, Sugisaki H, Saino T (2006) Effects of decadal climate change on zooplankton over the last 50 years in the western subarctic North Pacific. Glob Change Biol 12:907-920

> González-Solís J, Shaffer SA (2009) Introduction and synthesis: spatial ecology of seabirds at sea. Mar Ecol Prog Ser 391:117-120

- González-Solís J, Croxall JP, Wood AG (2000) Sexual dimorphism and sexual segregation in foraging strategies of northern giant petrels, Macronectes halli, during incubation. Oikos 90:390-398

Grémillet D, Dell'Omo G, Ryan PG, Peters G, Ropert-Coudert Y, Weeks SJ (2004) Offshore diplomacy, or how seabirds mitigate intra-specific competition: a case study based on GPS tracking of Cape gannets from neighbouring colonies. Mar Ecol Prog Ser 268:265-279

> Grémillet D, Lewis S, Drapeau L, van Der Lingen CD and others (2008) Spatial match-mismatch in the Benguela upwelling zone: Should we expect chlorophyll and seasurface temperature to predict marine predator distributions? J Appl Ecol 45:610-621

Hanawa K, Mitsudera H (1987) Variation of water system distribution in the Sanriku coastal area. J Oceanogr Soc Jpn 42:435-446

Hatch SA (1987) Copulation and mate guarding in the northern fulmar. Auk 104:450-461

Hayasi S (1966) A note on the biology and fishery of the Japanese anchovy Engraulis japonica (Houttuyn). Calif Coop Ocean Fish Invest Rep 11:44-57

Hébert PN, Golightly RT (2008) At-sea distribution and movements of nesting and non-nesting marbled murrelets Brachyramphus marmoratus in northern California. Mar Ornithol 36:99-105

Hill RD (1994) Theory of geolocation by light levels. In: Le Boeuf BJ, Laws RM (eds) Elephant seals: population ecology, behaviour and physiology. University of California Press, Berkley, CA, p 227-236

Hunt GL (1990) The pelagic distribution of marine birds in a heterogeneous environment. Polar Res 8:43-54

Igual JM, Forero MG, Tavecchia G, González-Solís J and others (2005) Short-term effects of data-loggers on Cory's shearwater (Calonectris diomedea). Mar Biol 146:619-624

Ito S (2002) Foraging areas of short-tailed shearwaters during their northward migration along the Pacific coast of northern Japan. Ornitholog Sci 1:159-162

> Iwahashi M, Isoda Y, Ito S, Oozeki Y, Suyama S (2006) Estimation of seasonal spawning ground locations and ambient sea surface temperatures for eggs and larvae of Pacific saury (Cololabis saira) in the western North Pacific. Fish Oceanogr 15:125-138

Jouanin C, Roux F, Mougin JL, Stahl JC (2001) Prelaying exodus of Cory's shearwaters (Calonectris diomedea borealis) on Selvagem Grande. J Ornithol 142:212-217

Kasai H, Saito H, Kashiwai M, Taneda T and others (2001) Seasonal and interannual variations in nutrients and plankton in the Oyashio region: a summary of a 10 -years observation along the A-line. Bull Hokkaido Natl Fish Res Inst 65:55-134

Kasai A, Kimura S, Nakata H, Okazaki Y (2002) Entrainment of coastal water into a frontal eddy of the Kuroshio and its biological significance. J Mar Syst 37:185-198

Kawai H (1972) Hydrography of the Kuroshio Extension. In: Stommel H, Yoshida K (eds) Kuroshio: its physical aspects. University of Tokyo Press, Tokyo, p 235-352

> Kimura S, Kasai A, Nakata H, Sugimoto T, Simpson JH, Cheok JVS (1997) Biological productivity of meso-scale eddies caused by frontal disturbances in the Kuroshio. ICES J Mar Sci 54:179-192

Kimura S, Nakata H, Okazaki Y (2000) Biological production in meso-scale eddies caused by frontal disturbances of the Kuroshio Extension. ICES J Mar Sci 57:133-142

Kitagawa T, Kimura S, Nakata H, Yamada H (2004) Diving behavior of immature, feeding Pacific bluefin tuna (Thunnus thynnus orientalis) in relation to season and area: the East China Sea and the Kuroshio-Oyashio transition region. Fish Oceanogr 13:161-180

- Komatsu T, Sugimoto T, Ishida K, Itaya K, Mishra P, Miura T (2002) Importance of the Shatsky Rise Area in the Kuroshio Extension as an offshore nursery ground for Japanese anchovy (Engraulis japonicus) and sardine (Sardinops melanostictus). Fish Oceanogr 11:354-360

Lewis S, Sherratt TN, Hamer KC, Wanless S (2001) Evidence of intra-specific competition for food in a pelagic seabird. Nature 412:816-819

Lewis S, Benvenuti S, Dall'Antonia L, Griffiths R and others (2002) Sex-specific foraging behaviour in a monomorphic seabird. Proc R Soc Lond B Biol Sci 269:1687-1693

Matsumoto K (2008) The relationship between long- and short-distanced foraging strategy and marine environment in chick-rearing streaked shearwaters. PhD thesis, Hokkaido University (in Japanese)

> Matsumoto K, Kazama K, Sato K, Oka N (2007) Estimation of breeding population size of streaked shearwaters on Sangan Island, Iwate, based on 3D topography by GIS. Jpn J Ornithol 56:170-175 (in Japanese with English Abstract)

Mihara Y (1998) Distribution of the Japanese anchovy, Engraulis japonicus, off southeastern Hokkaido. Sci Rep Hokkaido Fish Exp Stn 53:9-14 (in Japanese with English Abstract)

Nakamura K (1974) On a mass accidental death of the streaked shearwater in Sagami Bay. Bull Nanagawa Pref Mus 7:71-79 (in Japanese with English Abstract)

> Nakata H, Kimura S, Okazaki Y, Kasai A (2000) Implications of meso-scale eddies caused by frontal disturbances of the Kuroshio Current for anchovy recruitment. ICES J Mar Sci 57:143-152

Nihira A (1996) Studies on the behavioral ecology and physiology of migratory fish schools of skipjack tuna (Katsuwonus pelamis) in the oceanic frontal area. Bull Tohoku Natl Fish Res Inst 58:137-233

Ochi D, Oka N, Watanuki Y (2010) Foraging trip decisions by the streaked shearwater Calonectris leucomelas depend on both parental and chick state. J Ethol 28:313-321

Odate K (1994) Zooplankton biomass and its long-term variation in the western North Pacific Ocean, Tohoku sea area, 
Japan. Bull Tohoku Natl Fish Res Inst 56:115-173

Ogi H (1984) Feeding ecology of the sooty shearwater in the western subarctic North Pacific Ocean. In: Nettleship DN, Sanger GA, Springer PF (eds) Marine birds: their feeding ecology and commercial fisheries relationships. Canadian Wildlife Service, Ottawa, p 78-84

Ogi H, Ryu K (2001) Present status and future guideline for conservation of the streaked shearwater breeding population on Oshima Oshima Island, Hokkaido. Bull Fish Sci Hokkaido Univ 52:71-93

Ogi H, Kubodera T, Nakamura K (1980) The pelagic feeding ecology of the Short-tailed shearwater Puffinus tenuirostris in the subarctic Pacific region. J Yamashina Inst Ornithol 12:157-182

Oka N (2004) The distribution of streaked shearwater (Calonectris leucomelas) colonies, with special attention to population size, area of sea where located and surface water temperature. J Yamashina Inst Ornithol 35:164-188

Oka N, Suginome H, Jida N, Maruyama N (2002) Chick growth and fledgling performance of streaked shearwaters Calonectris leucomelas on Mikura Island for two breeding seasons. J Yamashina Inst Ornithol 34:39-59

- Olson DB (2001) Biophysical dynamics of western transition zones: a preliminary synthesis. Fish Oceanogr 10:133-150

Oozeki Y, Takasuka A, Kubota H (2007) Characterizing spawning habitats of Japanese sardine (Sardinops melanostictus), Japanese anchovy (Engraulis japonicus), and Pacific round herring (Etrumeus teres) in the northwestern Pacific. Calif Coop Ocean Fish Investig Rep 48:191-203

Peck DR, Congdon BC (2006) Sex-specific chick provisioning and diving behaviour in the wedge-tailed shearwater Puffinus pacificus. J Avian Biol 37:245-251

Phillips RA, Silk JRD, Croxall JP, Afanasyev V, Briggs DR (2004a) Accuracy of geolocation estimates for flying seabirds. Mar Ecol Prog Ser 266:265-272

Phillips RA, Silk JRD, Phalan B, Catry P, Croxall JP (2004b) Seasonal sexual segregation in two Thalassarche albatross species: competitive exclusion, reproductive role specialization or foraging niche divergence? Proc R Soc Lond B Biol Sci 271:1283-1291

Polovina J, Uchida I, Balazs G, Howell EA, Parker D, Dutton P (2006) The Kuroshio Extension Bifurcation Region: a pelagic hotspot for juvenile loggerhead sea turtles. DeepSea Res II 53:326-339

Qiu B (2001) Kuroshio and Oyashio Currents. In: Steele JH, Turekian KK, Thorpe SA (eds) Encyclopedia of ocean sciences. Academic Press, New York, NY, p 1413-1425

- Rayner MJ, Hauber ME, Clout MN, Seldon DS, Dijken SV, Bury S, Phillips RA (2008) Foraging ecology of the Cook's petrel Pterodroma cookii during the austral breeding season: a comparison of its two populations. Mar Ecol Prog Ser 370:271-284

Sakurai Y (2007) An overview of the Oyashio ecosystem. Deep-Sea Res II 54:2526-2542

Sassa C, Kawaguchi K, Oozeki Y, Kubota H, Sugisaki H (2004) Distribution patterns of larval myctophid fishes in the transition region of the western North Pacific. Mar Biol 144:417-428

Shaffer SA, Weimerskirch H, Costa DP (2001) Functional significance of sexual dimorphism in wandering albatrosses, Diomedea exulans. Funct Ecol 15:203-210

Shaffer SA, Tremblay Y, Awkerman JA, Henry RW and others (2005) Comparison of light- and SST-based geolocation with satellite telemetry in free-ranging albatrosses. Mar Biol 147:833-843

Shaffer SA, Tremblay Y, Weimerskirch H, Scott D and others (2006) Migratory shearwaters integrate oceanic resources across the Pacific Ocean in an endless summer. Proc Natl Acad Sci USA 103:12799-12802

Shiomi K, Ogi H (1992) Feeding ecology and body size dependence on diet of the sooty shearwater, Puffinus griseus, in the North Pacific. Proc NIPR Symp Polar Biol 5:105-113

> Sugisaki H, Kurita Y (2004) Daily rhythm and seasonal variation of feeding habit of Pacific saury (Cololabis saira) in relation to their migration and oceanographic conditions off Japan. Fish Oceanogr 13:63-73

Suryan RM, Sato F, Balogh GR, Hyrenbach KD, Sievert PR, Ozaki K (2006) Foraging destinations and marine habitat use of short-tailed albatrosses: a multi-scale approach using first-passage time analysis. Deep-Sea Res II 53:370-386

Takahashi A, Ochi D, Watanuki Y, Deguchi T and others (2008) Post-breeding movement and activities of two streaked shearwaters in the north-western Pacific. Ornitholog Sci 7:29-35

Takahashi K (2000) Fishery grounds with sea bird of Sendai bay in summer and autumn. Bull Miyagi Pref Fish 16:55-59

Takahashi M, Watanabe Y (2004) Developmental and growth rates of Japanese anchovy Engraulis japonicus during metamorphosis in the Kuroshio-Oyashio transitional waters. Mar Ecol Prog Ser 282:253-260

Takasuka A, Oozeki Y, Kimura R, Kubota H, Aoki I (2004) Growth-selective predation hypothesis revisited for larval anchovy in offshore waters: cannibalism by juveniles versus predation by skipjack tunas. Mar Ecol Prog Ser 278:297-302

Takasuka A, Kubota H, Oozeki Y (2008a) Spawning overlap of anchovy and sardine in the western North Pacific. Mar Ecol Prog Ser 366:231-244

Takasuka A, Oozeki Y, Kubota H, Lluch-Cota SE (2008b) Contrasting spawning temperature optima: Why are anchovy and sardine regime shifts synchronous across the North Pacific? Prog Oceanogr 77:225-232

Teo SLH, Boustany A, Blackwell S, Walli A, Weng KC, Block BA (2004) Validation of geolocation estimates based on light level and sea surface temperature from electronic tags. Mar Ecol Prog Ser 283:81-98

Tsuruta Y, Takahashi S (1997) Reproductive ecology of the Japanese anchovy (Engraulis japonicus H.) in the Kuroshio Extention and the mixed water region. Bull Hokkaido Natl Fish Res Inst 61:9-15

Wanless S, Harris MP (1993) Use of mutually exclusive foraging areas by adjacent colonies of blue-eyed shags (Phalacrocorax atriceps) at South Georgia. Colon Waterbirds $16: 176-182$

Warham J (1990) The petrels: their ecology and breeding systems. Academic Press, London

Warham J (1996) The behaviour, population biology and physiology of the petrels. Academic Press, London

> Weimerskirch H (2007) Are seabirds foraging for unpredictable resources? Deep-Sea Res II 54:211-223

> Weimerskirch H, Bartle JA, Jouventin P, Stahl JC (1988) Foraging ranges and partitioning of feeding zones in three species of southern albatrosses. Condor 90:214-219

Yamamoto T, Takahashi A, Yoda K, Katsumata N, Watanabe S, Sato K, Trathan PN (2008) The lunar cycle affects at-sea behaviour in a pelagic seabird, the streaked shearwater, Calonectris leucomelas. Anim Behav 76:1647-1652

Yamamoto T, Takahashi A, Katsumata N, Sato K, Trathan PN (2010) At-sea distribution and behaviour of streaked shearwaters (Calonectris leucomelas) during the nonbreeding period. Auk 127:871-881

Yasuda I (2003) Hydrographic structure and variability in the Kuroshio-Oyashio transition area. J Oceanogr 59:389-402

Yoshida N (1981) Ki ni noboru umidori: Kityo ohmizunagidori (Climbing the trees: streaked shearwaters with interesting behavior). Chobun sya Co. Ltd., Tokyo (in Japanese) 